\section{Play it Again, Hideaki \\ Using the Cel Bank in Neon Genesis Evangelion}

Ida Kirkegaard

The control room shakes dramatically. Makoto Hyūga looks over his shoulder to relay the newest information to his superiors in a hurried voice. Data flashes on multiple screens in rapid succession. Shigeru Aoba turns around to yell that his systems can no longer monitor the situation. Captain Misato Katsuragi tenses her brow. More data flashes on a slanted screen, an all-caps LOST central to the image. Maya Ibuki looks down into a monitor and reads that the pilot can no longer be contacted. Misato's eyes narrow with determination, and the viewer may suspect that she is thinking about her last resort plan to blow up the facility, herself, and everyone in the room if this mission fails. In the background, a choir is belting out the climactic stanza of Beethoven's “Ode to Joy." It's an intense sequence, rapidly cut and suffused with dread. But it's also rather familiar. Indeed, the attentive viewer of Neon Genesis Evangelion might be experiencing a certain feeling of déjà vu right now. Because every single bit of animation in this sequence from episode 24 is a bank cut.

In anime, the term 'bank' is typically used to refer to cuts of animation that, once created, are used again and again in different contexts (Association of Japanese Animations 2019: 50). 'Cut' in an animation context refers to a continuous segment of animation where the 'camera' does not switch its viewpoint, analogous to a shot in liveaction filmmaking (Cirugeda 20I7). These cuts are determined and named in storyboards and generally handled by a single key animator. In other words, bank cuts are short sequences of animation that are made for and then routinely reused in a production, drawn from
How to cite this book chapter: Kirkegaard, I. 202I. Play it Again, Hideaki: Using the Cel Bank in Neon Genesis Evangelion. In: Santiago Iglesias, J. A. and Soler Baena, A. (Eds.). Anime Studies: Media-Specific Approaches to Neon Genesis Evangelion. Pp. 49-83 Stockholm: Stockholm University Press. DOI: https://doi.org/Io.I6993/bbp.c. License: CC-BY 4.0 
a virtual 'bank' or 'vault.' While the phenomenon is similar to what is commonly known as stock footage, the two terms in Japanese are not used synonymously, with bank being used primarily in animation contexts to describe cuts made for and used within a specific series, while stock footage describes 'canned' footage from a central archive that can be used in several different productions.

This chapter provides an in-depth, inductive reading of Neon Genesis Evangelion focused on the use of bank cuts. The analysis is based on both the 2019 Netflix release and the 2015 Japanese BluRay release, as well as the official storyboard collections (Evangerion ekonte shī; GAINAX I997a-e, I998), and I will be referring to specific cuts by using their storyboard designations. For example, the oft-repeated shot of Misato drinking a beer discussed in a later section is denoted 2-CI23, meaning cut $\mathrm{I}_{2} 3$ from episode 2 (its first appearance). While the foundation of this study is a formal analysis of the material, its goal is not to replicate the work of so-called sakuga fans. These are fans of animation as a craft who meticulously catalog cuts of anime that they find particularly well-animated, and identify specific key animators from the animation alone (Suan 2018). While such in-depth knowledge of anime production can help shed light on otherwise unnoticed aspects of a work, the accumulation of such knowledge for its own sake is not the goal of this chapter. Instead, minute observations and production literacy are employed here to understand the work and its reception, that is, the formal analysis is connected to decoding the narrative and meta-narrative meanings of the material.

This chapter is divided into six sections: first, an introduction to the concept of realism in animation and theories that are particularly relevant to the case of EVA. Second, a summary of these theories as they relate to EVA. Third follows a discussion of the concept of 'the original' when it comes to the material being used for this analysis. The fourth section is a short history of bank cuts in anime. The fifth 
section is the first half of an analysis of EVA focusing on bank cuts as a genre trope and production necessity. And, finally, the sixth section is the second half of the EVA analysis, a more in-depth treatment of a few selected sequences whose use of bank cuts particularly illuminates anime's media specificity through realism, followed by a discussion of how this use of the cel bank relates to the overall themes and significance of the work.

\section{Anime's Realism}

In academia, it can be hard to justify paying close attention to the texts of popular media culture, in particular when it comes to elements of these texts that are mostly the result of suboptimal circumstances. A phenomenon like bank cuts might appear to be simply an accident to be ignored, an unfortunate effect of the fact that anime production is, above all else, fast and cheap. ${ }^{1}$ Indeed, the cheapness of anime in general can make it difficult to defend, characterized as it is by hurried, underfunded productions relying heavily on various forms of so-called limited animation. ${ }^{2}$ This positions anime as outside the realm of what is often considered the pinnacle of animation within both popular and academic discourse, Walt Disney and his studio.

The overall trajectory of the Disney Studio in the 2oth century was characterized by a move toward increasing sophistication with regard to embodied and character-specific movement. This new form of animation replaced the standardized and repetitive figurative movement of early animation, escalated the use of advanced mechanical tools such as the multi-plane camera to create movement into depth and, importantly, led to an ever-increasing adherence to a meticulous simulation of real-world physics (Crafton 20I2). Driving this development was Walt Disney's own desire to simulate the realism of live-action film in animation, the end product of which has been called not realism, but hyper-realism, the reproduction not of physical reality
I. In the interest of clarity, it is important here to remember that the term 'anime' does not have one single definition. For the purposes of this chapter, I follow the definition laid out in Berndt 2018 .

2. As for the latter, see Chapter I by José Andrés Santiago Iglesias. 
precisely, but of the reality of cinema itself (Steinberg 2014: 288). In time, due to the commercial and critical success of Disney's productions and their central role to much writing on animation, cel animation in general came to be seen in part as either adhering to or diverging from a standard set by Disney, one that included the understanding that to make advancements in animation was to move toward detailed full movement and a Disney-style realism, inadvertently positioning stillness, stylization and reused assets as lesser in the minds of many critics and animators.

Here, it is crucial to discuss the topic of realism and to first emphasize that there is no one comprehensive realism, but rather several realisms. Even within the field of Cinema Studies, several mutually competing perspectives on the relationship between animation and realism exist (Rowley 2005: 67). While it is an oft-repeated truism that the classic Disney style represents a pinnacle of realism, this is simply the viewpoint of what Rowley (2005) calls the 'quest for realism' narrative. Here, the purpose of animation is seen as simulating cinematic realism as much as possible, developing toward a simulacrum of reality that may not be indexical, but is visually so close to photographic realism as to be indistinguishable from it. Indeed, developments in this direction are still being made in much threedimensional computer-generated (3D CG) animation, driven in large part due to its foundation in engines and algorithms founded on meticulous reproduction of physics because they were originally developed to simulate a playable reality first for military training and then for video games (Bukatman 20I4: 3 I2).

While realism and drawings are not inherently opposed to each other-after all, pictorial realism has a long history in paintingthe founding assumption of many traditional theories of realism in Cinema Studies is the idea that cinema is the photographic reproduction of a profilmic reality, something animation can by definition never be (Rowley 2005: 66). Indeed, one might characterize the 
drive toward visual realism in animation as an asymptotic trajectory that can approach the photographic image, but will never reach it. This thinking underlies what Rowley (2005) names the 'inversion narrative,' a medium-specific argument about what animation 'should do' that emphasizes its potential for the fantastic over its potential for simulation. In his famous essay fragments, Sergei Eisenstein (I986) criticized the Disney studio's development, insisting that their later films had lost the revolutionary plasmaticness that the earlier, more malleable form of animation had embodied. The fundamental idea at play in Eisenstein's critique is that animation possesses the potential for other forms of expression than live-action cinema does, and that this fact means that doing so is what animation should focus on. As Rowley puts it: "Realism is not what animation is best at, such a position holds, and therefore works that show freer invention and fantasy are privileged" (2005: 66).

While these perspectives on the relationship between animation and realism are opposite in their approach to what animation should strive for, they are not mutually exclusive, and are often found simultaneously in writing on animation (Rowley 2005: 67). This largely reflects how the concept of realism itself is particularly slippery when it comes to animation. Animation, after all, has no profilmic reality to refer back to, and so the question of what is or should be the referent for any attempt at realism is rather more open than it is for live-action films. Comparisons can be made between the animated image and both the real world itself and live-action film's depiction of that reality, and those two referents are far from always in alignment (Rowley 2005: 68). More than that, however, Rowley takes a third option when he argues that the hyperreal environment of Disney's films is not simply a reproduction of cinematic realism, but a realer-than-real environment that is entirely fake, yet is presented and experienced as real. This 'world' is created by exaggerating reality through, for example, squash and stretch animation and 
overdetermined movements. Eventually, these movements and other aspects of the consistent Disney style have solidified into a set of 'codified conventions that are understood by audiences to connote reality, even while they clearly are not literally realistic' (Rowley 2005: 69). That is, more than its relation to the real world or to live-action cinema, the realism of Disney is defined by a set of internally consistent conventions that are accepted by the audience as depictions of the real, regardless of their actual relationship with physical reality.

Even more than Disney-style animation, anime's claim to realism may be considered contentious at best. Compounding the lack of indexicality and removal from photorealism it shares with all animation, with its reliance on limited animation and tricks like bank cuts, anime can hardly be said to comply to the Disney ideal of exaggerated hyperrealism either. Instead, traditional cel anime relies on its own system of codified visual representation that invites the viewer to quickly scan the image instead of being drawn into it (Steinberg 20I 2a: 6). Critic Eiji Ōtsuka has identified three kinds of realism in anime and related media: scientific, biological and manga-anime realism (Ōtsuka 2003). Scientific realism refers to drawings of mechanical things striving for a simulation of photographic realism. In other words, it is a form of pictorial realism not dissimilar from (a) pictorial realism in painting and (b) filmic realism, or indeed from the way Disney-style animation attempts to reproduce the movements of living things, despite being instead focused on mechanics. In robot series like EVA, the usage of this type of realism is a well-established convention, and one that stands in noticeable contrast to the more stylized character designs. Indeed, it is those 'hieroglyphic' character designs that provide the spark of Ōtsuka's second realism, biological realism. This idea stems originally from the work of manga pioneer Osamu Tezuka, who claimed that his characters with their large eyes and cartoonesque forms were semiotic, abstract drawings, divorced 
from any real-world referent (cited in Berndt 2013: 366; originally in Tezuka 1979).

Despite this, Tezuka's characters were realistic in the sense that they possessed physical, vulnerable bodies that could bleed and die. The oft-cited first example of this form of realism is a character in Tezuka's I945 short study manga Until the Day of Victory (Jp. Shöri no hi made) being shot and, rather than shrugging off the damage in a humorous way like the Looney Tunes characters he resembles, bleeding like a real person (Ōtsuka 2003: 217, cited in Steinberg 20I4: 29I). Biological realism is the antithesis of the archetypical immortal cartoon character, governed by the real-life physics of limited, vulnerable bodies rather than the limitless malleability of cartoon physics (Bukatman 20I4: 302). It is a realism that does not depend on a particular type of visuals as scientific realism does, but instead on narrative, that is, visually non-realistic characters suffering, bleeding and dying as human beings. This form of realism is invoked in the very first episode of $E V A$, when the character Rei Ayanami is introduced covered in bandages that leave blood on protagonist Shinji Ikari's hands as he touches her (\#I-290, GAINAX I997a). Of course, by the time EVA aired in I995, biological realism was a long-established part of anime and manga conventions and such a direct invocation would not have been strictly speaking necessary to make the audience expect that characters can bleed and die. Thus, its deliberate utilization here might be seen as a setting of expectations: not only can characters bleed and die in this series, they will.

Ōtsuka's third realism, coined in discussions of what are today known as light novels, but were then called character novels, is mangaanime realism. It is a realism which has as its referent not the real world, but the stylized yet internally consistent world of anime and manga, the environmental pervasiveness of which creates a sense of realness and plausibility for the viewer familiar with its conventions 
3. The I-novel (shishōsetsu) is a Japanese literary genre that developed during the Meiji period (I868-I9I2) under the influence of Western naturalism. I-novels emphasize interiority and autobiographical themes and are typically written in the first person. See, for example, Suzuki (I996).
(Ōtsuka 2003; Ōtsuka 20IO). In that way, it can be said to be similar to Disney's hyperrealism, which also replicates not the real world, but the 'world' of Hollywood cinema. Ōtsuka compares the low culture light novel to the high literature form of the I-novel, ${ }^{3}$ claiming that where the I-novel emulates the world of the 'author-as-I,' the light novel emulates the world of anime and manga in a similar way, in other words, while one draws from reality and the other from fiction, the two literary forms draw on their sources to construct their reality in the same way (according to Steinberg 20I4: 293). While Ōtsuka's emphasis is on the role of manga-anime realism as an interface between anime and its related media, the fundamental idea that the conventions and codes of anime can constitute an alternative but no less valid referent for the story world resonates strongly with Rowley's idea of an animation realism founded on codified conventions, and it is a particular interesting form of realism to examine when engaging with EVA.

\section{EVA's Realism}

To discuss realism in the context of EVA means to lean on Ōtsuka's and Rowley's conceptions of realism. This is, after all, a series where impossible giants controlled by thoughts fight alien monsters over underground bases built from the shell of the egg that originated all life on earth. Rather, EVA's baseline realism is very similar to the realism of Disney with its magical fairies, talking animals and wondrous transformations that nonetheless move and behave in ways that are so 'realistic' as to offend Eisenstein (Rowley 2005: 69). It is a realism that in Rowley's terms occupies positions on several different spectrums of realism-quite visually realist, but not particularly narratively realist, very character realist, but not very realist in terms of motion, at least not most of the time (Rowley 2005: 70). Importantly, the series' position on the spectrum of realism is mostly consistent, creating a believable, reliable portrayal of a particular story world, 
a diegetic realism the establishment of which is crucial for its later deconstruction. In Ōtsuka's terms, EVA strongly exhibits both scientific realism and biological realism. As mentioned above, EVA is full of characters who bleed, suffer and die as real people do, an aspect of the series' world established in episode I with the introduction of the injured, bleeding Rei Ayanami. Even the ostensible robots can and do bleed, and when characters die, they do not come back-or at least they should not, which makes it all the more jarring when Rei does come back from the dead in the later parts of the series. In terms of scientific realism, EVA sets up what appears to be a hard SF approach, constructing something that at least appears to be an internally consistent, scientifically plausible story world. Visually, vehicles, buildings, laboratories, computers, weaponry and giant robots are rendered in loving detail, reflecting the trivia-obsessed aesthetics of otaku culture and the historical conventions of the robot genre. Information about the ostensible science underlying the events of the series is given in rambling monologues by characters operating computers and carrying clipboards while data flashes on screens and hydraulic pumps push airlocks open. That none of this is based on actual science and draws more on esoteric kabbalah mysticism than anything truly scientific is in some ways beside the point: by presenting its made-up science in this way, EVA sets up the expectation that events will unfold according to, if not real science, then an internally consistent fantasy science. This is indeed the case when Rei Ayanami comes back from the dead-this break with biological realism is explained through the series' fantasy science, and there is a diegetic reason for her return to the land of the living.

When it comes to manga-anime realism, EVA's relationship to the conventions of the robot genre becomes particularly important. And in many ways, EVA adheres closely to these conventions: it features color-coded robots operating out of a paramilitary base to fight monsters that are initially designed very similar to the monsters fought by Ultraman. Its characters are designed according to anime aesthetics 
4. A moe character archetype originating in otaku subculture. Tsundere refers to a character, typically female, who initially appears harsh and cold (tsuntsun), but later acts warm and affectionate (deredere), especially toward the male protagonist.

5. Special Effects Films, specifically used to refer to Japanese live-action productions that rely heavily on suitmation and practical effects rather than stop-motion or CGI animation. The term is associated primarily with fantasy, Science Fiction and superhero works. Examples of tokusatsu are the Godzilla films, the Kamen Rider and Super Sentai TV series, and the Ultra series.

6. See also Chapter 7 by Zoltan Kacsuk.

7. See also Chapter 8 by Olga Kopylova. and embody types that were popular with fans at the time, such as the tsundere ${ }^{4}$ Asuka and the cool, reserved Rei. It employs a monsterof-the-week structure, meaning that a new enemy is introduced and defeated in (almost) every episode and the military action is juxtaposed with a relatable school dramedy set in the near future. EVA's world is a collage of popular tropes and conventions from previous anime, manga and tokusatsu $u^{5}$ productions, assembled with a nerdy fervor befitting the notoriously otaku-aligned director Hideaki Anno and Studio GAINAX. All of this intertextuality and adherence to convention establishes a strong manga-anime realism, an anime-style hyperrealism that is internally consistent and resonant with those familiar with the tropes it employs.

On the other hand, EVA is also a work that is commonly cited as transgressive of the conventions of anime, both in general and when it comes to the specific genre of robot anime. In particular, it is often described as a work that overcomes the perceived inherent childishness and immaturity of robot anime and uses the repetitive nature of the genre to subvert the expectations of the viewers, using formula and conventionality to "lull the audience into complacency" before undermining that complacency by breaking the formula (Bolton 20I8: 224). EVA is often portrayed as being particularly ruthless in its critique of the otaku (hardcore fans) who formed the core of its most dedicated audience and indeed most of its creators (Shamoon 20I 5: I05). ${ }^{6}$ Hiroki Azuma (2009) famously claimed that otaku consumed media in a new, postmodern way where detached 'database' analysis and emotional empathy were simultaneously possible due to the loss of the idea of a grand narrative behind the individual works consumed. ${ }^{7}$ This approach to media also meant that otaku may be the people best able to truly accept manga-anime realism as a form of realism, engaging fully with the conventions and codes of anime as a valid referent for portrayals of character interiority. And while the characterizations of transgression tend to refer primarily to the 
structure of EVA, particularly the conventions of the robot genre that the series is famously said to subvert, EVA also plays with and subverts the series' own construction of realism throughout the series and particularly toward the end.

\section{Defining the Materials}

When analyzing a work based on something as relatively minute as bank cuts, minor differences between versions can dramatically alter the analysis and the ultimate understanding. Defining the 'definitive' source is crucial here, but when dealing with TV anime, that is not an easy task, and EVA is representative of that issue. On the most basic level, this chapter engages only with the 26-episode series, first broadcast 4 October I995-27 March I996 on TV Tokyo. It does not take into account the theatrically released recap film Neon Genesis Evangelion: Death \& Rebirth (Shin seiki Evangerion gekijōban: Shi to shinsei, 1997), the newly animated alternative episodes 25 and 26 released theatrically as End of Evangelion (Shin seiki Evangerion gekijöban: Ealmagokoro o, kimi ni, I997), nor the much later films in the Rebuild of Evangelion series: Evangelion I.o: You Are (Not) Alone (Evangerion shin gekijōban: Jo, 2007), Evangelion 2.0: You Can (Not) Advance (Evangerion shin gekijōban: Ha, 2009), Evangelion 3.0: You Can (Not) Redo (Evangerion shin gekijöban: Q, 2012) and Evangelion: $3.0+I . O$ (Shin Evangerion gekijöban: II, 202I). There is doubtlessly much to be said about the way both $E o E$ and in particular Rebuild meticulously recreate certain bank cuts from the series, but that is outside the scope of this chapter.

However, simply defining the TV series as material is easier said than done. When it comes to deciding what to highlight and what to exclude, particularly in the case of EVA, one must contend with the question of originality. Even the initial TV series is not one unchanging work. Rather, it has been edited, altered and re-edited over the last 
25 years, ranging from edits for international distribution undertaken by third parties to deliberate re-cutting tackled by creators deeply involved in the original production. As an example of the former, the 2019 Netflix release of the series edits the ending song Fly Me to the Moon out of every episode, as well as two cases where it is used as background music within the series. This editing appears to have been done for licensing reasons, but only outside of Japan, meaning that the version a viewer will experience changes depending on ISP address. That this editing has taken place is not disclosed in any way by the platform, leaving viewers who have not seen the series previously unaware that they are watching an altered version. In fan discourse, such editing is typically seen as unwanted meddling by third parties, a relatively uncomplicated question of tainting the original. Unsurprisingly, the Netflix release was indeed met with fan outrage (Vilas-Boas 20I9). In an age where streaming has become the primary way most people consume media, Netflix's alterations of EVA have consequences for the wider perception of the work, as it is the only version that has been made available to the general public outside Japan in almost 15 years, and the edits are not disclosed. This means that, for the average viewer, whatever Netflix presents is EVA, and they have no reason to question that it is the original, or at least the definitive version of the material.

The malleability of streaming media, where a video may change overnight without any easily discernible trace of alteration, complicates critical analysis. In the specific case of EVA, mass-market physical releases of the series featuring both original and re-edited versions of all episodes continue to be produced for the Japanese market, making the issue of version availability less of universal concern than one that waxes and wanes with the observer's access to Japanese releases of physical media. ${ }^{8}$ Outside Japan, however, no physical release of the

8. EVA was last released on Japanese Blu-Ray on 24 July 2019. series exists except for long-out-of-print DVDs released in the mid2000s (Vilas-Boas 2019). Thus, the Netflix release with its obscured 
alterations is the only way the vast majority of the world's population can legally access EVA.

But even with knowledge of what cuts Netflix have and have not made to EVA, can we actually define what the original version of the series is? While one might assert that obviously, the version that was broadcast on TV Tokyo in I995-96 is the original and everything else is an alteration, looking at EVA's release history prior to the Netflix release reveals that when it comes to $E V A$, the question of what version is 'original' and 'definitive' is not entirely straightforward. The recap film Death of Rebirth is particularly relevant to that discussion, aside from being an interesting play with the conventions of TV anime in and of itself. The term 'recap' or 'compilation' film refers to theatrically released features created primarily or entirely from pre-existing cuts of a particular TV anime, recut so that, ideally, the film can function as an alternative, shorter version of the same story (Sevakis 2016). Recap films are a long-standing convention in TV anime production, and at least initially they served as a way to make an anime series available beyond its initial television run, aside from the obvious financial benefits of releasing a film without having to produce much, or any, new animation. Early examples of recap films include Heidi, Girl of the Alps (Nakao, 1979) and the very successful Mobile Suit Gundam film trilogy (Tomino, I98 I-82). Despite the ubiquity of home video and streaming, recap films are still produced to this day (prominent examples from recent years include the $20 \mathrm{I} 2$ Madoka Magica and 201 8 Made in Abyss features) and their ubiquity seems to prove that they have come to occupy an established position as a convention of anime production. Recap films often, if not always, feature a few new cuts of animation alongside the recycled cuts from the TV series, as well as alterations to the music and compositing of the cuts, all serving to 'fix' perceived shortcomings of the TV version, whether those were the result of a rushed production or simply unpopular with fans. Rarer examples like Macross: Do You Remember 
Love (Kawamori, I984) even present the TV series' story through entirely new animation.

Death o Rebirth follows the recap film tradition by combining recycled cuts with new cuts, but rather than reassembling the material into a simple truncated version of the original storyline, the film also drastically reorganizes the material, presenting it in a thematic order. This shifts the emphasis from chronological storytelling (already jettisoned in the last two episodes of EVA) toward inward-facing character portraits. The events of the story are retold focusing not on when or how they occurred, but on how they affected the central characters. This renders Death \& Rebirth nigh incomprehensible for an audience not already familiar with the series, thus deliberately failing the expected purpose of a recap film entirely. The nature of this recap film has interesting parallels with the use of bank cuts in the initial series, but more importantly for the immediate discussion is the fact that the new cuts created for Death \& Rebirth were later edited into the TV series itself when it was released on laserdisc. This updated version of the TV series is often called the director's cut version, but only episodes $2 \mathrm{I}-24$ were altered in this way. ${ }^{9}$ The cuts inserted in these episodes were subsequently removed from Death \& Rebirth when that film was re-edited into the TV movie Shin seiki Evangerion gekijoban: DEATH (TRUE) (Anno, I998) and the freshly animated EoE. Subsequent releases of the series have largely preserved this division of the new material, rendering it part of the series proper and not the film. While in most countries Netflix presents episodes $2 \mathrm{I}-24$ in the director's cut rather than the broadcast version, they did not initially appear on Netflix when logged in from an ISP address in Japan, further muddling the question of what the 'original' version of

9. The director's cut versions of these episodes are distinguished from the broadcast versions with an apostrophe, thus episode $2 \mathrm{I}^{\prime}$ is the director's cut version of episode $2 \mathrm{I}$. this material is. To complicate the question more, the commercially released Evangelion ekonte shü storyboard collections also reproduce the storyboards for DEATH (TRUE) ${ }^{2}$ rather than the original Death o Rebirth, suggesting that the former, not the latter, is considered the 
definitive version of the material. Meanwhile, the same storyboard collections present the broadcast versions of episodes $2 \mathrm{I}-24$, not the director's cut versions of the same material, raising the question of where the cuts originally introduced in Death \& Rebirth truly belong. Taking the storyboard collections as an authority, the answer to that question seems to be 'nowhere.' All of this suggests that, ultimately, there is no one true 'original' version of the material, and so it is all the more important that researchers name and define which version they are working with. As mentioned above, this study relies both on the Netflix release and the Japanese Blu-Ray release of EVA, and I have included the director's cut sequences into my definition of the TV series even if their intended place within the franchise ultimately remains muddled.

\section{A Short History of the Bank System}

While this chapter uses the name 'bank cuts,' there are several different terms for the same phenomenon, including 'image bank' and 'cel bank.' The latter term hints at the reason why bank cuts are and have been so ubiquitous in anime: using them in a production saves cels, the single frames painted on celluloid sheets that were photographed one by one to create pre-digital 2D animation (Clements 20I3: 49). This is useful for TV productions operating under strict limitations of budget and production time, where reusing cels frees scarce resources to be used on other cuts. Even in today's digital age, reusing cuts saves time and work, as every second filled with bank cuts is a second of air time that does not need to be created anew and passed through the numerous complicated steps from storyboard to filming (Association of Japanese Animations 2019: 50). In the I980s, when American TV stations routinely commissioned animation from Japan, a half-hour TV cartoon for the US market consisted of I 2,000 cels per episode. Meanwhile, comparable anime productions made at the same studios 
for the domestic market were allowed 5,000 cels at best, going as low as I,200 for certain productions (Watanabe 2019). This made cel-saving measures such as bank cuts particularly important for anime production compared to other forms of animation.

The effect of these limitations can be observed in the landscape of TV anime both old and new. Perhaps most striking is the ubiquitous use of bank cuts in magical girl series aimed at young girls, such as Sailor Moon (Satō, I992). These series, almost to a fault, will include at least one elaborate transformation sequence that is repeated in every single episode, and often, in series featuring multiple heroines, up to five banked transformation sequences will be played in succession, taking up a significant amount of the episode's runtime. Sailor Moon in particular also relies on banked special attacks, speeches and even entire scenes repeated over and over again in its formulaic episodes. An example of this are the monster creation scenes, run at roughly the midpoint of every episode with only minor adjustments and often humorous changes to the dialogue, which mark each episode's transition from a school comedy to a superhero story. A similar if not as universal use of bank cuts is seen in anime aimed at young boys, where robots and monsters have equally long and elaborate transformation sequences, attacks and speeches. A recent example of this can be seen in the children's robot anime Shinkansen Henkei Robo Shinkarion (Ikezoe, 20I 8), where CGI bank cuts are extensively used to portray the robots launching and transforming. Indeed, bank cuts have come to be particularly associated with the robot genre as it has evolved through the years (Association of Japanese Animations 2019: 50).

It is interesting to note that this type of bank usage is often both conspicuous and elaborate, with bank cuts being assigned to senior key animators and paired with attention-grabbing theme songs and catchphrases for the audience to repeat at the playground. These are often gorgeous cuts, and their weekly repetition in already repetitive 
narratives aimed at children seem to take on a form of ritual quality. This is further suggested by the way anime aimed at a teenage or older audiences sometimes use similar bank scenes as a form of genre tribute. Examples of this can be seen in the transformation scenes of Magical Girl Lyrical Nanoha (Simbo, 2004). This series, drawing on magical girl genre conventions, but targeting an audience of adult men, includes elaborate transformation scenes in the style of those in Sailor Moon, but they are repeated only occasionally. Other genre pastiches, such as Madoka Magica (Simbo, 20II), do not repeat their transformation scenes at all, and as such they are not actually bank cuts, despite otherwise following the conventions of the format.

Beyond transformations and special attacks, bank cuts are still ubiquitous in anime, although their presence is less conspicuous. Studying production materials is often the most reliable way to identify bank cuts in these instances, as cuts may be drawn from disparate episodes and, especially in digital productions, obscured through digital filters or color changes. While they are common across all genres, the exact utility of bank cuts differs depending on the needs and format of a production. Due to their lack of identifying background details, emotional close-ups might be drawn from the bank, as is the case in Candy Candy (Imazawa, I976), which otherwise contain very few bank cuts. Meanwhile, a series such as Mobile Suit Zeta Gundam (Tomino, I985) relies on a small bank of standard robot action cuts to enhance its fight scenes (Watanabe, 20I9). Bank cuts might also be used in marginal but still time-filling segments like the postcredits scene in Card Captor Sakura (Asaka, 1998-2000) which repeats the same few cuts of the character Kero talking to the audience in every episode.

Like so many other characteristic traits of TV anime, the ubiquity of bank cuts can be traced back to the Mushi Pro studio and the Astro Boy TV series (Tezuka, I963). Even if it was not strictly invented for 
the series, Osamu Tezuka called it his 'bank system,' a term still commonly in use today, referencing the star system of reoccurring character designs he used in his manga (Clements 20I3: I 20). The bank system was just one of the many forms of limited animation the series relied on to meet its weekly schedule and keep somewhat within its very limited budget. Being a robot series, Astro Boy was also particularly suited to limited animation and bank cuts. As Marc Steinberg has pointed out, the main character's jet-propelled flying was convenient in its lack of need for any movement beyond a dynamic still image dragged across a background (Steinberg 20I2b: 76). Flight as a form of locomotion detached from physical surroundings and the minimalist futurist backgrounds of Astro Boy's world made it easier for the animators to insert the banked cuts into various episodes than if Astro Boy had, for example, commuted on a bicycle or swung through his city like Spider-Man. The strong connection between the highly influential robot anime Astro Boy and bank cuts can be seen as one plausible reason for the connection between genre and the ubiquity of bank cuts, which becomes particularly noticeable in the case of EVA.

\section{Bank in EVA}

As a TV anime, particularly one from the mid-I990s, EVA utilized bank cuts as a matter of production necessity. Their frequency increases over the course of the series' run until the final two episodes, which famously are comprised of little but bank cuts. Structurally, EVA's form lends itself well to bank cuts, featuring as it does a small number of recurring locations and characters, as well as adopting, on the surface level, the repetitive monster-of-the-week structure typical to parts of the robot genre. One noticeable point about the use of bank cuts in EVA is that they are unevenly placed, that is, some types of sequences are much more likely to use bank cuts than others. 
Combat sequences contain few to no bank cuts, even late in the series, and only rarely do sequences of character interaction contain anything but newly animated cuts (one rare exception can be seen in episode $2 \mathrm{I}$, where a situation recurring from episode $\mathrm{I} 5$ is highlighted through the use of bank cuts). Instead, bank cuts are primarily seen in two types of sequences: light, domestic and comedic sequences, and the conventional Science Fiction sequences taking place in the NERV control room and SEELE meeting chamber.

The domestic sequences that take place in Misato Katsuragi's apartment are particularly prone to containing bank cuts. This is a location introduced in the second episode and, with the exception of one sequence in episode 23 , the only private home seen in the series. This location fills the role of 'home' in the series to such an extent that when Shinji imagines a family home, something he has never truly had, in episode 26, the exterior of Misato's house is explicitly used, cementing the symbolic meaning of this location (GAINAX I997e: 528). The sequences in Misato's apartment use and reuse some very distinct bank cuts, often cued with the same musical theme, which serve to build a sense of familiarity that is similar to the role typically played by establishing shots. In several cases, for example, an instantly recognizable cut of Misato drinking a beer (Fig.2.I), first seen in episode 2 (2-cI23 in the storyboard), is used to establish a sequence as taking part in her kitchen and set a mood that is, at least on the surface, one of sitcom-like light-heartedness and warmth (GAINAX i997a: I86).

Even more conspicuous in their use of bank cuts than these domestic sequences, however, are the sequences taking place in the NERV control center. Here, often intercut with moments of high action, commanders and technicians bark orders, react in shock and recite largely meaningless pseudoscientific data about the Angels, the Evas or the situation at hand, while graphic user interfaces signal synch rates, alerts and critical emergencies. These sequences use a small 

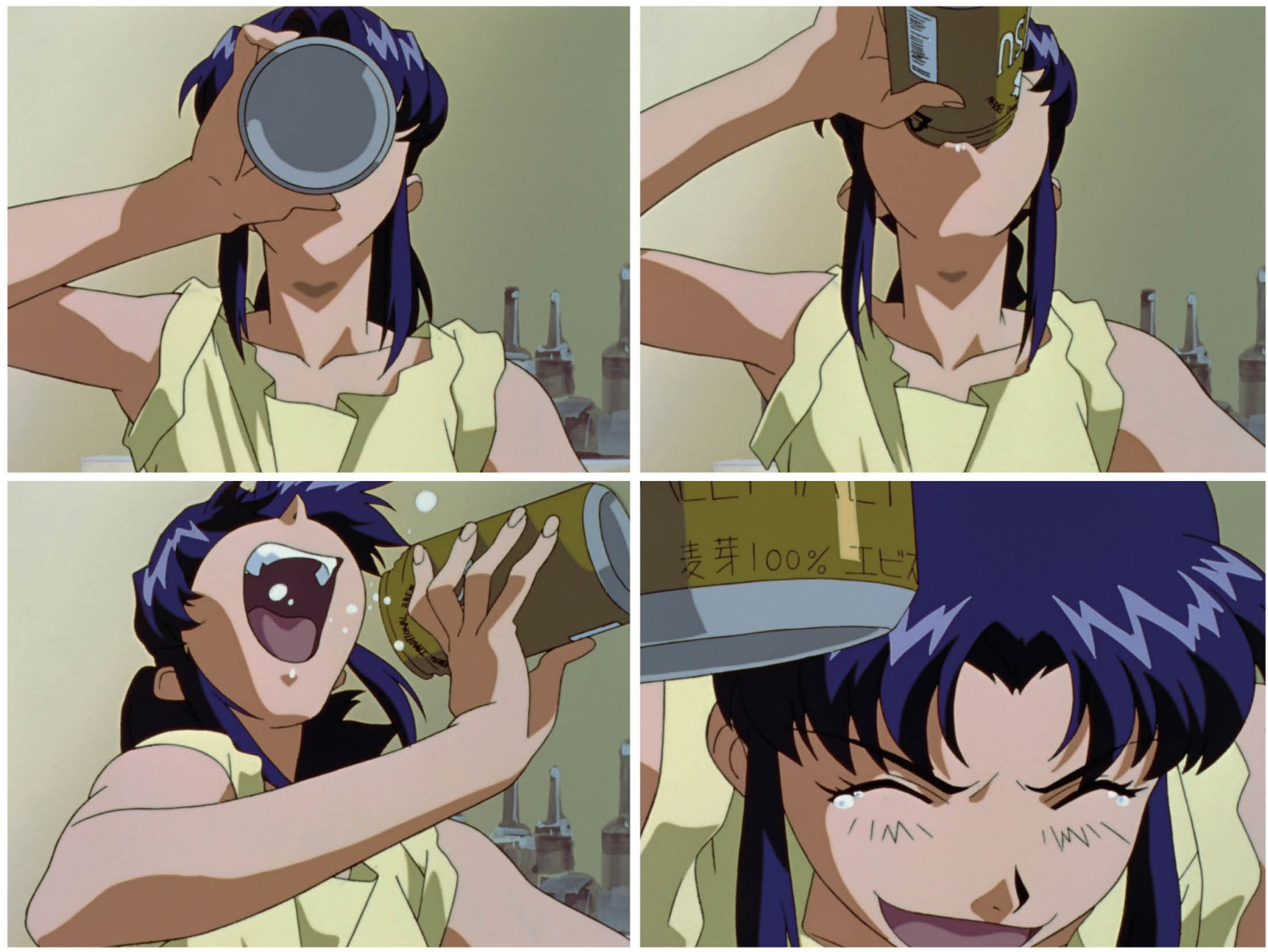

Figure 2.1. The cut of Misato Katsuragi drinking a beer appears for the first time in episode 2. (C) khara, inc. number of shots over and over again, mostly sourced from episodes 2 (the first time a battle is shown in the series) and I4 (an episode set entirely within this location). Particularly noticeable as bank cuts are a group of shots showing the command technicians turning around and talking (Fig.2.2), while other shots are subtler and only stand out as repeated if the viewer pays closer attention. These shots are 

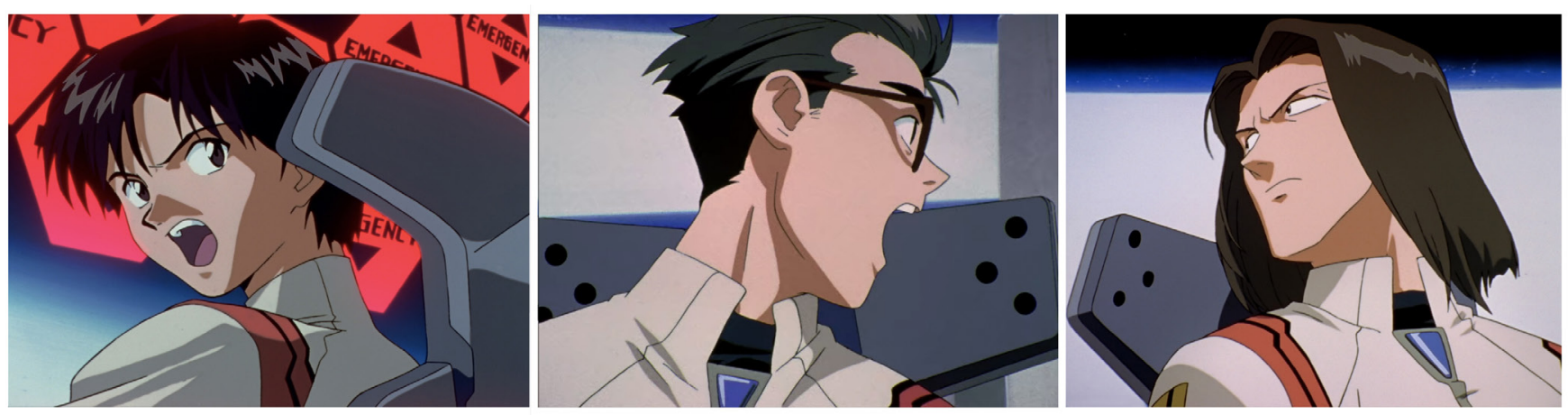

reused again and again with only the dialogue replaced, creating a strong sense of continuity between the different Angel attacks, no matter their precise form or severity. In fact, as the production progresses, the volume of bank cuts used in these sequences grows until the final battle sequence, which contains just two new cuts taking place in the control room (24-c234 and 24-c262), out of about 60 cuts (GAINAX I997e). True to form, however, even in this late and presumably resource-strapped episode, the action taking place outside the control room is comprised almost entirely of newly animated cuts. This kind of resource distribution falls in line with the philosophy of Mushi Pro-style limited animation, ebbing and flowing between high and low energy rather than spreading limited resources evenly over the running time (Steinberg 20I 2b: 34).

What types of sequences are comprised of bank cuts also determines which are not, and in EVA's case those are the earlier mentioned action sequences and the sequences of emotional, non-comedic interaction between characters. While that might seem obvious at first glance-what else would an ostensible robot action series allocate its animation resources to if not the battle sequencesthis spread is by no means universal. As mentioned above, anime such as Sailor Moon (Satō, I992) and Mobile Suit Zeta Gundam (Tomino, I985) repeatedly rely on bank cuts in action scenes.

Figure 2.2. The cuts of the NERV technicians turning around are first seen in episode 2. () khara, inc. 
EVA's action sequences, meanwhile, are high quality set-pieces, a showcase for the skill of the animators and a key selling point of the series itself.

The control room sequences with their high number of bank cuts seem to largely be an artifact of the conventions of the robot genre. Control room sequences are an established and expected trope in this genre, often recurring in every episode alongside the fight of the week as part of the rhythm of the series. They enhance the tension of the fight and provide commentary for the audience, but they are not part of the main action itself and do not need as much unique animation to do their job. They also tend to feature the same characters, wearing the same uniforms in the same location, over and over again. For all of these reasons, control room sequences lend themselves especially well to bank cuts. And while their recurrence is not quite as schematic as in children's robot anime such as The King of Braves GaoGaiGar (Yonetani, I997), where certain bank cuts repeat almost on the same minute each week, EVA's control room sequences and their reoccurring rhythm still constitute an important aspect of the series' relationship with robot anime genre conventions.

Interestingly, EVA seems to approach the recurring nature of these sequences somewhat ironically. Throughout the storyline, Angel attacks disable the headquarters in various ways, but each time, the characters manage to carry on to the extent that the same bank cuts can be employed. In a striking move toward the end of the series, when the control center itself is destroyed, the characters relocate to a henceforth unmentioned secondary control center that just so happens to be identical to the original-and the same bank cuts are reused again. The recurring nature of the control room sequences forms an interesting contrast to the increasingly horrifying occurrences in the Angel fights themselves: no matter what is happening, the control room is almost eerily unchanging, the cuts are the same, in EoE even 
when approaching the end of the world. That is to say, even as the narrative heads into territory far away from the then typical themes of robot anime, the control room sequences continue unabated, emphasizing the tie between the unfamiliar ground the story is treading and its genre roots. The use of bank cuts in this case ends up being a reinforcement of this effect: as characters, stakes and environments change drastically, the control room stays the same, literally, because it is depicted through the same exact cuts of animation as it was back in episode 2.

\section{Bank and Anime-Specific Realism}

As mentioned earlier, EVA is a work that repeatedly undermines and calls into question its own constructed realism. This is most noticeable toward the end of the series, where characters start entering into close contact with the Angels and the series' mostly consistent use of scientific and biological realism in its portrayal of the characters and their surroundings gives way to highly abstract, expressive portrayals of their mental landscapes. In these episodes, long sequences depict the minds of the characters being probed, presented largely through monologues in a dark featureless space, dialogues superimposed over still images, abstract lines and plain text taking the place of figurative drawings of characters. In the final two episodes, as everyone worldwide comes into contact with one another and the Angels through the Third Impact, this break from EVA's particular brand of scientific realism is supplemented with others, such as photographic still images, rough pencil sketches and a sequence that eventually breaks down into loose production materials, culminating in pans over a script accompanied by voiced lines. In another sequence, the main character is given freedom over the shape of his own body and surroundings, morphing into all sorts of different forms without suffering any harm, reduced in a way to a more primal, plasmatic state 


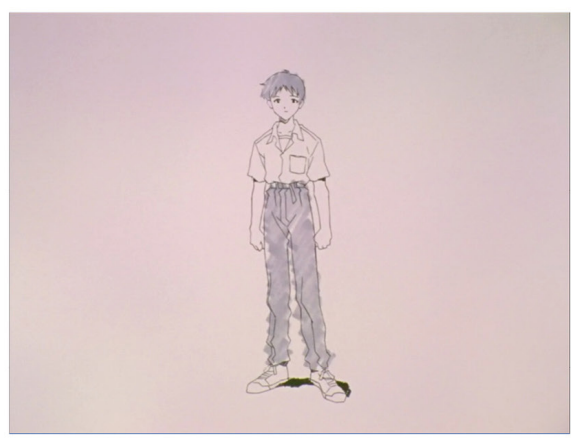

Figure 2.3. Shinji Ikari's form morphs plasmatically in episode 25 . (C) khara, inc.
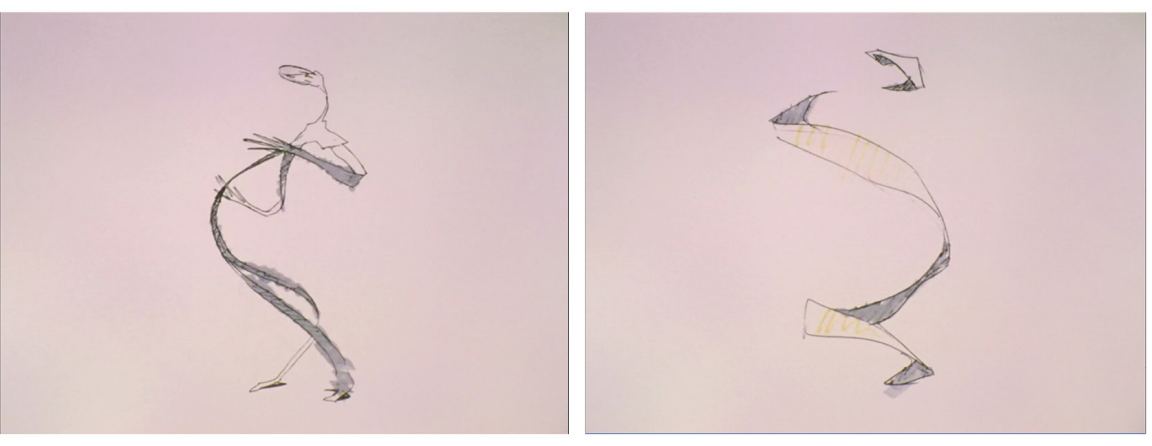

(Fig.2.3). These sequences stretch the credibility of the series' own claim to biological realism to its breaking point by highlighting the non-indexical nature of the characters and removing their physical bodies, either by distortion or by simply taking them away and leaving only the script.

A very similar, albeit less spectacular, effect is achieved even earlier in the series through two distinct usages of bank cuts. The first of these, by far the most frequent, is the way very conspicuous bank cuts are reused with new dialogue in introspective sequences, crucially and unlike the control room sequences discussed earlier, with no serious attempt being made to hide the fact that these cuts are indeed bank and do not combine into a realistic diegetic whole.

Two examples of this, sharing a very noticeable number of bank cuts, can be seen in episodes I 6 and 25. Here, a cut of Asuka wearing a towel (\#I6-ci I, GAINAX I997d), originally used in one of the previously mentioned sequences in Misato's kitchen, is repurposed and twisted in introspective sequences as the dialogue associated with the footage changes (Fig.2.4a). In the cut's original context, a relatively mundane sequence in Misato's kitchen, Asuka is talking to Misato, scolding her for being 'too soft' on Shinji, and for getting together with her ex-boyfriend, Kaji, whom Asuka herself has been dating previously, albeit unsuccessfully. This follows immediately after a sequence of cuts where Asuka berates Shinji for apologizing too 

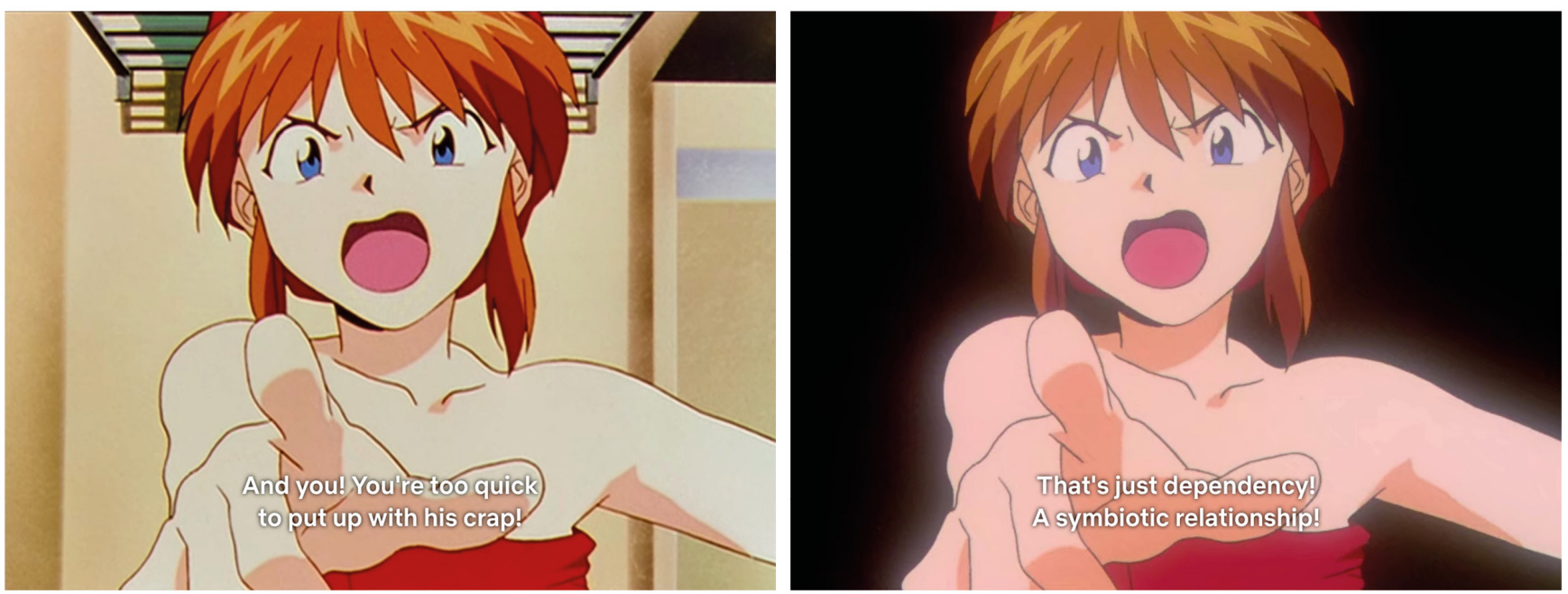

much, and one where she simply complains about the temperature of the bath water. In the wider context of the series, this is a cut that is about Asuka herself and her need to take out her own frustrations on other people, particularly in this part of the narrative, where her confidence has been eroded after a series of setbacks. But as the cut is recontextualized, its meaning shifts subtly from being about Asuka to being about Shinji's impression of her. When the same cut reappears later in the same episode, Shinji has been swallowed by an Angel during battle and is speaking with a disembodied voice (that calls itself the Shinji that exists within his mind) about his guilt and self-blame. Then, two blatantly unrelated bank cuts of Asuka-one wearing a T-shirt, the other the above-mentioned \#I6-cII-appear, overdubbed with new dialogue of Asuka blaming Shinji for his self-deprecation. When the cut reappears in episode 25 , it is in the narrative context of Instrumentality, a process that removes all barriers between people. Shinji is sitting alone in a black room, talking to a vision of Asuka who appears in several different bank cuts that seem to have been reassembled with no intention of creating a believable
Figure 2.4. The same cut of animation is repurposed in different contexts and with altered dialogue in episode I6. () khara, inc. 
continuity between them, her outfit changing with every cut back to Shinji. This time, Asuka scolds Shinji for his loneliness and dependency on others, and it is worth noting that, unlike in the previous example, the background from Misato's apartment has now been replaced with the same black nothingness in front of which Shinji is depicted (Fig.2.4b).

Importantly, and unlike the control room bank sequences, these examples all come from sequences where a character is conversing not with another character, but with their own impression of that other person, something that is explicitly spelled out in the series (during the previously mentioned sequence in episode I6) as 'the me in your mind.' Shinji, the viewpoint character in these examples, is not talking to Asuka, but to a memory of his own impressions of her. Here, the very conspicuous use of bank cuts works to emphasize this effect. The reuse of the same section of animation makes it very clear that the 'Asuka' appearing in the sequence is not supposed to be read as an autonomous character or individual, but an assemblage of impressions of that person. The use of new dialogue, however, also distinguishes this use of bank cuts from the tried-and-true trick of replaying cuts to signify a memory. While these cuts may seem like memories, the dialogue is new and unique to this sequence, not a replay of anything said earlier. Likewise, the selection of cuts to create these dialogues with what is ostensibly a character through bank cuts highlights that Asuka is not supposed to actually be there-her outfit, and sometimes her location, as signified by the background, changes with every cut, breaking the illusion of realism. In the episode 25 sequence, all cuts of Asuka are bank (except for \#25-c93 and \#25-C105, which show her in the same frame as Shinji), while every shot of Shinji except one (\#25-cIO4, recycled from \#2-c-32I) is newly drawn, strongly suggesting that the effect is intentional. There is an uncanny, malleable quality to these repeated cuts that works to show the treacherous quality of memories and impressions of 
others. It is a memory of Asuka, speaking in Asuka's voice-but it is not Asuka.

Bank cuts are used in this way several times throughout the series, most prominently in episode 25, where not only Shinji but several other characters are subjected to similar 'interrogations' by their own impressions of other characters, all rendered through recombined bank cuts. It is perhaps worth noting that the narrative context of these sequences is also similar-unlike the conventional use of bank cuts in the control room sequences noted above, where cuts are assembled to support the illusion of a coherent world, these fluttering, reassembled characters appear in sequences where the series is depicting an inner, psychological world rather than a physical one.

One particular sequence, one of the above-mentioned director's cut additions originally part of the Death \& Rebirth film, provides a unique use of bank cuts that perhaps more than any other highlights their potential as a tool to play with the construction of reality in anime. In this sequence from the extended cut of episode 22, Asuka is fighting the $5^{\text {th }}$ Angel, Arael, a floating creature in low Earth orbit. The Angel's psychic attack hits her and she is thrown into an abstract interrogation where her mind and memories are probed by the Angel, breaking down her sense of self and will to fight. Visually, the sequence is similar to the previous interrogation of Shinji, taking place in a black void, but how the bank cuts are used is significantly different. Following a flashback related to her past, a voice we are meant to assume belongs to Asuka's mother (who in her childhood rejected her in favor of a doll) asks her the question "Who are you?" Immediately, a sequence of four bank clips of Asuka are played, the original backgrounds replaced with alternating solid black and red: her self-introduction to her new classmates (Fig.2.5a, from episode 8), an angry glare at Shinji (Fig.2.5b), a smug expression (Fig.2.5c, also from episode 8) and a desperate, sexual plea to be noticed by Kaji (Fig.2.5d, from the extended version of episode 22). The sequence 

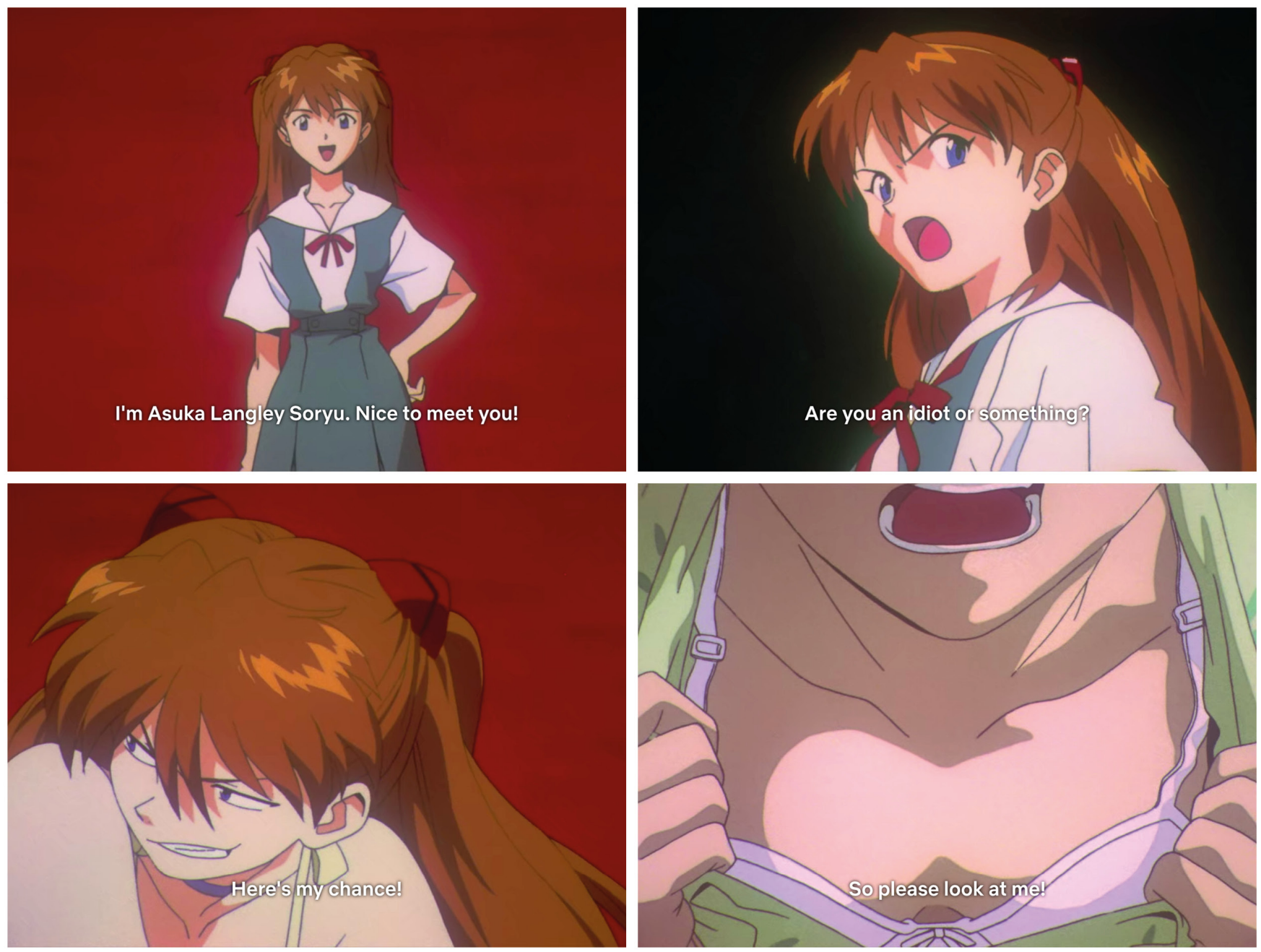

Figure 2.5. Four bank cuts are recycled multiple times with different voice actors reading the same lines in episode 22. (C) khara, inc. ends with a new cut of Asuka screaming "No! That's not me!", and immediately starts over. This sequence of cuts is replayed five times. Unlike in the previous example, the lines of dialogue are unaltered. However, in these five repetitions of the same few cuts, the role of Asuka is played not by her usual voice actress Yūko Miyamura, but by the five actresses who play the other main female characters in 
EVA: Mitsuishi Kotono (Misato Katsuragi), Megumi Hayashibara (Rei Ayanami), Miki Nagasawa (Maya Ibuki), Yuriko Amaguchi (Ritsuko Akagi) and Junko Iwao (Hikari Horari). It is interesting to note that Megumi Ogata, the woman who plays the male main character Shinji, is noticeably absent among these alternate Asukas, suggesting that it is the characters, not the actresses, who are taking over Asuka's identity in this sequence. ${ }^{10}$

While in terms of narrative and tone this sequence and the ones mentioned earlier have little in common with the Tom and Jerry cartoon used by Bukatman (20I4) as an example, the sudden break from an otherwise mostly realist form is similarly jarring in these late-series sequences. But where in Tom and Jerry the result of the striking break with realism is comedy, in EVA it is something quite different. Instead, the shock to EVA's realism created by repeated cuts paired with unexpected vocals creates a sense of wrongness and unease that reinforces the narrative events. The on-the-surface unspectacular replacement of Asuka's voice with that of another actress highlights the artificiality of her identity as a character. This can be read both in connection to the narrative, where Asuka is fighting an assault on her personal barriers, and as a deliberate questioning of the construction of reality within the series itself.

In the sequence under scrutiny here, the division between visuals and voice in animation, and specifically in anime, is employed in tandem with bank cuts to question the claim to realism of the cuts. In anime specifically, the illusion of a natural connection between sound and image is potentially even more tenuous than in other forms of animation, as sound is recorded after the animation is finished. This means that unlike in classic American animation, where sound is recorded first and lip movement is painstakingly animated to create an illusion of a natural connection, in anime lip flaps are highly abstract. Because of this gap, we really have no evidence to suggest that any of these 'other Asukas' are 'not me' beyond the voice of Yūko Miyamura
Io. See also Chapter 4 by Minori Ishida. 
screaming that they are, and as such, this use of bank cuts, instead of being simply a cheap trick, serves to call into question Asuka's personal identity and depict what is happening narratively through the form of the animation itself.

It would be easy to analyze this sequence, and indeed many sequences in the last quarter of EVA, as the animation revealing its own trick, drawing our attention to the artificial nature of everything happening on screen and the fact that Asuka is, in fact, not a person, but simply an assemblage of painted celluloid and film trickery, voiced by an interchangeable actress. One could even point to the readings of EVA that emphasize its challenge to the otaku audience and claim that the point of this sequence is to show them that the world of anime they are so invested in is nothing but an illusion. However, I argue that the series is doing the very opposite. After all, otaku are fully aware of the reassembled, constructed nature of the anime they love, and no less able to feel strong emotions for its characters regardless (Azuma 2009). This is not a sequence where the veil is pulled back and whatever empathy the viewer might have felt for the character is revealed as a misdirected, sad obsession with an unfeeling construct of which the viewer is instructed to let go. Rather, through the narrative and voice performance, the viewer is asked to further empathize with Asuka as her reality is unraveled, and the visual unraveling presented through the use of bank cuts enhances that feeling as not only Asuka's identity, but the viewer's perception of the indexical connection between her component parts, sound and vision, is distorted. If we accept that anime conventions can be used as a referent for realism, as Ōtsuka's concept of manga-anime realism postulates, the distortion of this realism here portrays not simply a construction being torn down, but reality itself being destabilized. The viewer is expected to accept manga-anime realism as realism and react to the unraveling of this realism as one would react to the real world coming undone; in other words, feeling what the characters are feeling in an empathetic, inward-facing way that would 
not be easy, or perhaps possible, to replicate through even the most impressive CGI effects. Rather than detachment, in other words, this break from the baseline realism of EVA through the simple use of bank cuts creates empathy, and showcases through the form of the animation itself what the narrative is about in these sequences, namely, the deconstruction of reality, identity and certainty as humans meet Angels and all personal boundaries are broken down in Instrumentality.

\section{Conclusion}

For reasons that are mostly connected to the economic realities of anime production, EVA is a series that relies heavily on labor-saving forms of limited animation typical to anime. These include the focus of this chapter, bank cuts, that is, cuts of animation recycled in various new contexts often paired with new dialogue. The series uses these in both genre-typical ways and as a deliberate tool during certain sequences in the latter half of the narrative where they are employed as part of a collection of breaks from the reality the series has been constructing.

While EVA's stylized character designs and limited movement may be seen as less realist than photorealist CGI imagery or the embodied acting of a Disney film, the series adheres to all three of Ōtsuka's anime-typical realisms. Through the employment of scientific, biological and manga-anime realism, EVA constructs an internally consistent alternative reality that the otaku spectator is prone to accept as real. In specific sequences in the second half of the series, however, the use of bank cuts highlights the constructed nature of this alternate world by breaking the rules of realism that were used to construct it. In this way, EVA is able to depict the breaking down of reality itself in a particularly visceral way that echoes and emphasizes the events of the narrative-and of the outside, social world. 


\section{References}

Association of Japanese Animation [Nihon dōga kyōkai] (ed.). (20I9). Animēshon yōgo jiten. Tokyo: Rittorsha.

Azuma, H. (2009). Otaku: Japan's Database Animals. Minneapolis, MN: University of Minnesota Press. (Introduction and translation by J. E. Abel and S. Kono).

Berndt, J. (2013). Ghostly: 'Asian Graphic Narratives,' Nonnonba, and Manga. In D. Stein and J.-N. Thon (eds.), From Comic Strips to Graphic Novels: Contributions to the Theory and History of Graphic Narrative (pp. 363-384). Berlin: deGruyter. . (201 8). Anime in Academia: Representative Object, Media Form, and Japanese Studies. Arts, 7(4), 56. Retrieved from: DOI: https://doi.org/I0.3390/arts7040056

Bolton, C. (2018). Interpreting Anime. Minneapolis, MN: University of Minnesota Press.

Bukatman, S. (20I4). Some Observations Pertaining to Cartoon Physics; or, the Cartoon Cat in the Machine. In K. Beckman (ed.), Animating Film Theory (pp. 30I-3 I6). Durham, NC: Duke University Press.

Cirugeda, K. (20I7, I I January). SakuQ\&A: Anime Industry and Produc-

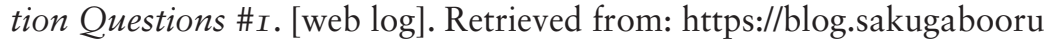
.com/20I $7 / 0$ I/I I/sakuqa-anime-industry-and-production-questions-I/

Clements, J. (2013). Anime: A History. London: Palgrave Macmillan.

Crafton, D. (2012). Shadow of a Mouse. Berkeley, CA: University of California Press.

Eisenstein, S. (1986). Eisenstein on Disney. Ed. Jay Leyda. Kolkata: Seagull Books.

GAINAX. (I997a). Shin Seiki Evangerion ekonte shū I. Tokyo: Fujimi Shobō. Shobō.

. (1997b). Shin Seiki Evangerion ekonte shū 2. Tokyo: Fujimi . (I997c). Shin Seiki Evangerion ekonte shū 3. Tokyo: Fujimi Shobō. 
. (I997d). Shin Seiki Evangerion ekonte shū 4. Tokyo: Fujimi Shobō.

. (r997e). Shin Seiki Evangerion ekonte shū 5. Tokyo: Fujimi Shobō.

. (1998). Shin Seiki Evangerion gekijōban ekonte shū. Tokyo: Fujimi Shobō.

Ōtsuka, E. (2003). Atomu no meidai: Tezuka Osamu to sengo manga no shudai. Tokyo: Tokuma Shoten.

. (2010). World and Variation: The Reproduction and Consumption of Narrative. (Introduction and translation by Marc Steinberg).

Mechademia, 5, 99-I I6.

Rowley, S. (2005). Life Reproduced in Drawings: Preliminary Comments upon Realism in Animation. Animation Journal, I3, 65-85.

Sevakis, J. (2016) Answerman: Why Are Compilation Films Made? Anime News Network. Retrieved from: https://www.animenewsnetwork.com lanswerman/2016-I2-02/.109367

Shamoon, D. (20I 5). The Superflat Space of Japanese Anime. In E. Lim and L. Chee (eds.), Asian Cinema and the Use of Space: Interdisciplinary Perspectives (pp. 93-108). London: Routledge.

Shin Seiki Evangerion Blu-ray BOX STANDARD EDITION. (n.d.). Retrieved from: https://www.evangelion.co.jp/ng.html

Steinberg, M. (20I 2a). Inventing Intervals: The Digital Image in Metropolis and Gankutsuō. Mechademia, 7, 3-22. DOI: https://doi.org/IO.I353 /mec.20I2.0003.

. (2012b). Anime's Media Mix: Franchising Toys and Characters in Japan. Minneapolis, MN: University of Minnesota Press.

. (20I4). Realism in the Animation Media Environment:

Animation Theory from Japan. In K. Beckman (ed.), Animating Film Theory (pp. 287-300). Durham, NC: Duke University Press.

Suan, S. (2018). Consuming Production: Anime's Layers of Transnationality and Dispersal of Agency as Seen in Shirobako and Sakuga-Fan Practices. Arts, 7(3), 27. Retrieved from: DOI: https://doi.org/I0.3390 larts7030027. 
Suzuki, T. (1996). Narrating the Self: Fictions of Japanese Modernity. Stanford, CA: Stanford University Press.

Vilas-Boas, E. (2019). Anime Classic Neon Genesis Evangelion Is Finally on Netflix. So Why Are Some Fans Upset? Vulture. Retrieved from: https://www.vulture.com/2019/o6/neon-genesis-evangelion-netflix -controversy-explained-guide.html

Watanabe, H. (2019). Interview with the author.

\section{Films and Series}

Bishōjo senshi Sailor Moon. Directed by Jun'ichi Satō and Kunihiko Ikuhara. Toei Animation, I992-97.

Card Captor Sakura. Direkted by Morio Asaka. Madhouse, I998-2000.

Chōjikū yōsai Macross: Ai, oboete imasu ka. Directed by Shōji Kawamori. Tatsunoko, I984.

Evangerion shin gekijōban: Jo. Directed by Hideaki Anno. Khara, 2007.

Evangerion shin gekijōban: Ha. Directed by Hideaki Anno. Khara, 2009.

Evangerion shin gekijōban: Q. Directed by Hideaki Anno. Khara, 2012.

Gekijō-ban alps no shōjo Heidi. Directed by Sumiko Nakao and Isao Takahata. Zuiyo Eizo, I979.

Kidō senshi Gundam I. Directed by Yoshiyuki Tomino. Sunrise, I98I.

Kidō senshi Gundam II: Ai senshi. Directed by Yoshiyuki Tomino. Sunrise, I98I.

Kidō senshi Gundam III: Meguriai sora. Directed by Yoshiyuki Tomino. Sunrise, I982.

Kidō senshi zeta Gundam. Directed by Yoshiyuki Tomino. Sunrise, I9 $85-86$.

Kyandi Kyandi. Directed by Tetsuo Imazawa. Toei Animation, I976-79.

Mahō shōjo Madoka Magika. Directed by Akiyuki Simbo. Shaft, 2o I I.

Mahō shōjo ririkaru Nanoha. Directed by Akiyuki Simbo. Seven Arcs, 2004 . 
Shin Evangerion gekijōban: II. Directed by Hideaki Anno. Khara, 202I.

Shin seiki Evangerion. Directed by Hideaki Anno. GAINAX, 1995-96.

Shin seiki Evangerion gekijōban: DEATH (TRUE)². Directed by Hideaki Anno. GAINAX / Production I.G, I998.

Shin seiki Evangerion gekijōban: Ealmagokoro wo, kimi ni. Directed by Hideaki Anno. GAINAX / Production I.G, I997.

Shin seiki Evangerion gekijōban: Shi to shinsei. Directed by Hideaki Anno. GAINAX / Production I.G, I997.

Shinkansen henkei robo Shinkarion THE ANIMATION. Directed by Takahiro Ikezoe. OLM, Inc., 20I8-I9.

Tetsuwan Atom. Directed by Osamu Tezuka. Mushi Production, I963-66.

Yūsha Ō Gaogaigā. Directed by Yoshitomo Yonetani. Sunrise, I997-98. 